Revista Brasileira de Informática na Educação - RBIE Brazilian Journal of Computers in Education (ISSN online: 2317-6121; print: 1414-5685) http://br-ie.org/pub/index.php/rbie

$\begin{array}{llll}\text { Submission: 04/03/2021; } & 1^{\text {st }} \text { round notif.: 07/05/2021; } & \text { New version: 25/05/2021; } & 2^{\text {nd }} \text { round notif.: 01/06/2021; } \\ \text { Camera ready: 02/06/2021; } & \text { Edition review: 03/06/2021; } & \text { Available online: 13/06/2021; } & \text { Published: 13/06/2021; }\end{array}$

\title{
Educational Digital Games integrated into Remote Labs: systematic and mapping reviews
}

Carinna Nunes Tulha
University of Campinas
c193014@dac.unicamp.br

\author{
Marco Antonio Garcia de Carvalho \\ University of Campinas \\ magic@unicamp.br
}

\author{
Vitor Rafael Coluci \\ University of Campinas \\ coluci@unicamp.br
}

\begin{abstract}
Remote laboratories and digital games are consolidated learning technologies. Recent works have demonstrated synergistic effects when these technologies are integrated. In this work, we performed systematic and mapping reviews to determine how is the state of the art of the integration process of remote labs and educational digital games. The reviews were carried out by using interdisciplinary databases following well established reviewing protocols. We found 13 papers with the systematic review and 20 with the mapping review. These papers were organized into four groups: (1) Theoretical, (2) Proposal, (3)Prototype, (4) Validation. Our findings showed the integration of these technologies is still in the beginning, since most of the sum of works on theoretical concepts, initial propositions or prototypes is still large than the works on validated results. We found trends towards integrated learning tools based on remote laboratories and digital games but these works are scarce, spatially concentrated and, in most cases, unavailable for massive use.
\end{abstract}

Keywords: Remote experimentation, game based learning, taxonomy, STEM. 


\section{Introduction}

Science, Technology, Engineering and Mathematics (STEM) education requires practical experiences during the learning process (Nedic, Machotka, \& Nafalski, 2003). Usually provided by universities, experiments and demonstrations in science laboratories are used to encourage practical tasks and to teach technical skills. However, high-quality science laboratories are normally expen-sive to build and to keep for most universities in underdeveloped and developing countries. On the other hand, information and communication technologies have emerged as facilitating tools and become important educational technologies.

Introduced in the '90s, remote laboratories allow the interaction with real experiments located in another place through the internet (Müller \& Erbe, 2007). Remote laboratories are online platforms from which the users can control parameters, run the experiment and see the results in real time by video streaming, and download data for post-processing (Casini, Prattichizzo, \& Vicino, 2003). Depending on the teacher's need, different activities may be proposed in the same remote experiment, enabling use at various educational levels. Differently from simulations and virtual laboratories, remote labs use a real equipment and, therefore, they are influenced by the surrounding environment, giving to students a virtual presence in the laboratory (Nedic et al., 2003). Because of their characteristics, the remote labs are very appropriate for realization of practical activities in hybrid teaching. The manipulation of the experiment can happen through different ways as, for instance, directly from an online platform, through virtual worlds or virtual reality. Also, the experiment can be responsive and visualized through computers and smartphones.

Digital games are also consolidated technologies used in many contexts, from just entertainment to learning. In education, games appear as alternatives or support to traditional methods. Good learning experience for students (players) and interest to the game is achieved with a balance of didactic features and game elements (Iturrate et al., 2013). Moreover, interaction characteristics of games such as instant feedback and rewards for success also help motivating students during the learning process (Pivec \& Kearney, 2007).

In 2001, Prensky et al. used for the first time Digital Game Based Learning (DGBL) to express the combination of the motivation of games and curricular contents (Papastergiou, 2009). The new generation of students, called digital native, interacts with technologies at an early age and $20 \%$ of them have their first contact with technologies between the ages of 5 and 8 years (Oblinger, 2004). Therefore, the students assumed that it was natural to use technologies during the daily activities, including in the school. DGBL is an approach to satisfy the student 's interests and habits, exploring the possibility to make the learning process more motivational instead of "dry" and "technical" (Prensky, 2003).

Remote laboratories and digital games can be initially thought as separate learning technologies but recent works have demonstrated synergistic effects when these technologies are integrated (Callaghan, McCusker, Losada, Harkin, \& Wilson, 2013), (Hoffmann et al., 2016), (Zualkernan, Husseini, Loughlin, Mohebzada, \& El Gaml, 2013) . Figure 1 illustrates screenshots of educational games that are integrated with remote labs. Despite the increase of the integrated use of remote laboratories and digital games, systematic reviews of this theme are lacking. Thus, this work presents a systematic and a mapping reviews of the integrated use of remote laboratories and digital games. Our main goal was to answer the following questions: (i) Is it possible to 
effectively integrate STEM remote laboratories and digital games? (ii) Is there any standard integration methodology? (iii) Are there real cases of the use of remote labs and digital games in class?

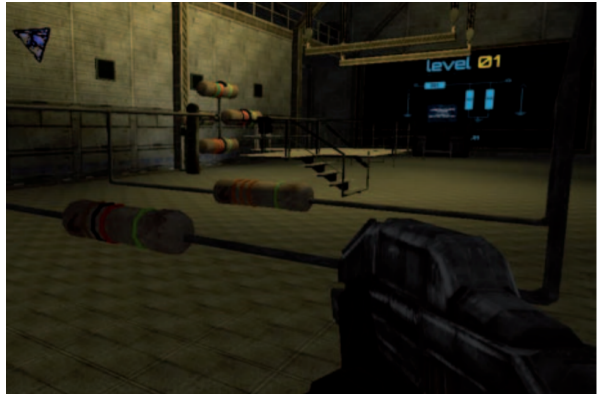

(a)

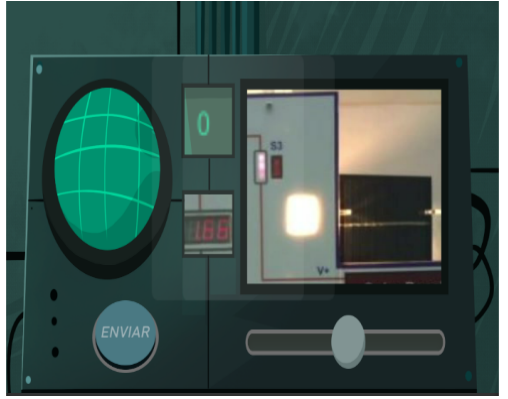

(b)

Figure 1: Example of digital games integrated to remote laboratories: (a) Circuit Warz first level (series/parallel circuit). Source: (Callaghan et al., 2013). (b) Fotovolt sixth phase (remote experiment manipulation). Source: (Tulha et al., 2019) .

To accomplish our goal we performed a systematic and a mapping reviews using several databases. Systematic and mapping reviews are survey methods with different focuses, specific protocols, and different execution phases. A systematic review is a survey technique of papers, aiming to identify the existence of studies and findings of some subject available in the literature. In these reviews, the study admits the summary of evidence according to a specific strategy (Sampaio \& Marcini, 2007). On the other hand, a mapping review allows identifying quantity, types, and results of an available literature finding. The difference between mapping review from the other models is that no specific outcomes or experimental designs in the studies are considered but it helps to create a classification that yields to a systematic map (Petersen, Feldt, Mujtaba, \& Mattsson, 2008). Therefore, the use of the same search terms in each method is expected to find different studies.

We expect that our paper can contribute to:

- determine the state of the art and trends of the integration of remote laboratories and digital games through systematic and mapping reviews;

- overview of remote laboratories merged with digital games focused on STEM area;

- group the main findings of the integration of remote laboratories and digital games based in the contributions facet and categories of research descriptions;

- overview the open challenges of the integration methods.

The rest of this paper is organized as follows: section 2 presents the systematic and mapping review protocols, section 3 shows the results and discussions considering their outcomes; finally, section 4 presents some conclusions. 


\section{Methodology}

The following subsections describes the systematic and mapping reviews protocol used during our work. The free software START (State of the Art Through Systematic Review) ${ }^{1}$ was used in the selection and extraction phases. START aims to support the application of systematic review based on Kitchenham's outlines and allows the users to fill in the information of the review protocol (Fabbri et al., 2016).

\subsection{Systematic Review}

We used the protocol proposed by Kitchenham (Kitchenham, 2004) to carry out our systematic review. The protocol is organized into three phases: planning, conduction, and extraction. We chose remote laboratory, game, and game-based learning as the controllers and remote labs and remote experimentation as the non-controllers. Thus, a search was performed by using the research query: (("remote experiment" OR "remote experimentation" OR "remote laboratory" OR "remote lab") AND (game OR "game based learning")). This query was applied on the interdisciplinary databases SciELO, Web of Science, Scopus, Proquest, Engineering Village, Science Direct, IEEE, and Learn Tech Lib. The screening process was based on the inclusion criteria that considered only researches that explicitly mentioned the integration between remote laboratory and games and availability of access, excluding proceedings papers, meeting abstracts, editorial materials, papers which the terms appear only as keywords, and papers found in different bases. In order to collect the maximum of papers on the subject, neither the publication year nor the educational level which the technologies were applied were specified.

\subsection{Systematic Mapping}

We applied a systematic mapping review based on the methodology suggested by Bailey (Bailey et al., 2007), which involves four phases. First, the definition of the research question. Second, the definition of the research strategy which includes the conducted search and paper screening. Third, the keywording of abstracts, a process that facilitates the classification of the papers. And, fourth, the data extraction and the creation of a map to summarize the evidences found.

To obtain an overview of the research area, the terms 'remote laboratories' and 'game' and their writing variations were considered in the research strategy to produce the following search query: (("remote experiment" OR "remote experimentation" OR "remote laboratory" OR "remote lab") AND ("game"). According to Bailey, the query should contain no terms related to methods or theories, which made us to exclude terms like "game-based learning" in the query. The same databases and inclusion/exclusion criteria used for the systematic review were also used for the systematic mapping review.

\footnotetext{
${ }^{1}$ http://lapes.dc.ufscar.br/tools/start_tool
} 


\section{Results}

The following subsections present the survey articles outcomes. After the systematic review the papers were organized chronologically, considering the description of collected papers objectives, didactic focus, and enhancement. The systematic mapping outcomes were organized into four groups, summarized as tables, and reflected at a bubble plot.

\subsection{Systematic Review Outcomes}

The primary research of the systematic review yields 458 papers, 404 not duplicated. Table 1 presents the number of papers surveyed in each phase of the review. Most of them (261) were obtained from the Web of Science database. After applying the inclusion and exclusion criteria, based on the analysis of the title, keywords, and abstract, the number of relevant papers was reduced to 19. After the extraction phase,when all sections of the papers were read, only 13 papers were accepted, most of them (7) found in IEEE.

Table 1: Number of papers found during the systematic review.

\begin{tabular}{cccc} 
Database & Primary Survey & Selection & Extraction \\
\hline SciELO & - & - & - \\
Engineering Village & 24 & 3 & - \\
IEEE & 23 & 7 & 7 \\
Learn Tech Lib & 15 & 1 & 1 \\
Proquest & 58 & 1 & - \\
Science Direct & 31 & - & - \\
Scopus & 46 & 12 & 5 \\
Web of Science & 261 & 1 & - \\
\hline Total & 458 papers & 19 papers & 13 papers
\end{tabular}

Most of the researches groups of the accepted papers are in Europe, especially in Spain, where 5 papers were produced in the University of Deusto (Table 2). The most cited article has 36 citations, out of the average of 4 citations per article. The oldest study found was from 2011. It was a paper that provides guidelines for the integration process, including a gaming model, elements of learning, and challenges, and that makes evident the possibility to effectively integrate remote laboratories into educational digital games (Dziabenko \& García-Zubia, 2011). In this paper, Dziabenko \& Garcia-Zúbia describe how remote laboratories works, the definition of the gamebased learning model and the main aspects to design an educational game. They concluded that elements such as the pedagogical approach, the tasks, the pedagogical support, the storytelling, the balance of challenges and the motivation should be considered during the development of a educational game.

Among the accepted papers, three present ideas of future works, including two proposals of a new remote labs architecture. Gil et al. (Rodriguez-Gil, García-Zubia, \& Orduña, 2016) propose a generic architecture of online labs models as a dissertation theme. The proposal is based on collaborative gamified remote lab immersed into Learning Management Systems. The dissertation aimed to provide support to modern features into remote labs, the development of complex labs, and a collaborative environment. Cano et al. (Cano, Hernández, Ros, \& Tobarra, 2016) proposed an architecture of a distributed remote lab combining game and instructional supplements 
Table 2: Papers chronologically.

\begin{tabular}{|c|c|c|c|c|c|}
\hline Year & Objective & Didactic Focus & Enhancement & Times cited* & Source \\
\hline 2011 & $\begin{array}{l}\text { Review of principles to guide } \\
\text { the integration process } \\
\text { (Dziabenko \& García-Zubia, 2011) }\end{array}$ & - & - & 10 & [A] \\
\hline 2011 & $\begin{array}{l}\text { Implemented a competition game, } \\
\text { evaluating the technical and pedagogical } \\
\text { efficiency (Atanasijevic et al., 2011) }\end{array}$ & Multivariable control & ECHO learning & 12 & {$[\mathrm{~A}]$} \\
\hline 2012 & $\begin{array}{l}\text { Describes the validation of a methodology } \\
\text { to the use of game-based } \\
\text { remote labs (Zualkernan et al., 2012) }\end{array}$ & Proportional integral & - & 1 & {$[\mathrm{~A}]$} \\
\hline 2013 & $\begin{array}{c}\text { Validation of a collaborative } \\
\text { remote lab (Zualkernan et al., 2013) }\end{array}$ & Proportional integral & - & 3 & {$[\mathrm{~B}]$} \\
\hline 2013 & $\begin{array}{l}\text { Describes a robot platform prototype } \\
\text { to multidisciplinary school } \\
\text { applications (Iturrate et al., 2013) }\end{array}$ & $\begin{array}{l}\text { Basic programming, } \\
\text { algorithm }\end{array}$ & Google Blockly & 8 & {$[\mathrm{~A}]$} \\
\hline 2013 & $\begin{array}{l}\text { Development and tests of Circuit Warz } \\
\text { project: virtual world with AC remote } \\
\text { panel challenges (Callaghan et al., 2013) }\end{array}$ & Circuit theory & - & 36 & {$[\mathrm{~A}]$} \\
\hline 2014 & $\begin{array}{l}\text { Implementation and layout of a remote } \\
\text { robot integrate into a logic puzzle } \\
\text { (Guenaga et al., 2014) }\end{array}$ & $\begin{array}{l}\text { Programming, logic } \\
\text { and debugging }\end{array}$ & Augmented reality & 3 & {$[\mathrm{C}]$} \\
\hline 2015 & $\begin{array}{l}\text { Implement a robot and evaluated the } \\
\text { preferences during the use of a } \\
\text { game control (Hoffmann et al., 2016) }\end{array}$ & Engineering practice & $\begin{array}{l}\text { Virtual Reality } \\
\text { Gamepad control }\end{array}$ & 4 & {$[\mathrm{C}]$} \\
\hline 2015 & $\begin{array}{c}\text { Evaluation of LaboREM: a robot arm } \\
\text { controlled through a collaborative game-like } \\
\text { environment (Luthon \& Larroque, 2015a) }\end{array}$ & Build circuits & - & 11 & {$[\mathrm{~A}]$} \\
\hline 2016 & $\begin{array}{c}\text { Propose a distributed remote lab based } \\
\text { in an instructional and motivational } \\
\text { game design (Cano et al, 2016) }\end{array}$ & Cybersecurity & - & 2 & {$[\mathrm{C}]$} \\
\hline 2016 & $\begin{array}{l}\text { Propose an generic remote lab architecture } \\
\text { as a dissertation theme (Rodriguez-Gil et al., 2016) }\end{array}$ & - & - & - & {$[\mathrm{C}]$} \\
\hline 2016 & $\begin{array}{c}\text { Describes the RALfie project and } \\
\text { the proposal of a peer-to-peer architecture through } \\
\text { quest-based learning (Kist et al., 2016) }\end{array}$ & - & - & 1 & {$[\mathrm{C}]$} \\
\hline 2019 & $\begin{array}{l}\text { Describes the development and } \\
\text { implementation of Fotovolt, based on } \\
\text { Photovoltaic effect (Tulha et al., 2019) }\end{array}$ & - & - & - & {$[\mathrm{A}]$} \\
\hline
\end{tabular}

[A] IEEE [B] Learn Tech Lib [C]Scopus

The number of citations were obtained until Fev/2021

using puzzle pieces. The architecture is based on Gagne's event model $^{2}$ to support cybersecurity and protection systems. To evaluate the student's motivation, the ARCS (Attention, Relevance, Confidence, and Satisfaction) model ${ }^{3}$ will be used as the basis for creating user experi-ence questionnaires. In another context, Kist et al. (Kist et al., 2016) propose the structure of the RALfie (Remote Access Laboratories for Fun, Innovation, and Education) project. RALfie allows the development of remote experiments by the users themselves and validates experiments or activities through gamification and quest-based learning methods. The control of the experiment request programming skills of the user. RALfie uses a peer-to-peer architecture that makes possible users to build remote laboratories knowing the basic underline technology.

In 2013, Callaghan (Callaghan et al., 2013) described the initial version of Circuit Warz, a game based learning merge with virtual worlds aiming the support of STEAM area education. The virtual world was created in Second Life and is also integrated into a Learning Management

\footnotetext{
${ }^{2} \mathrm{http}$ //epubstep.info/conditions-of-learning-written-content-ebook-robert-m-gagne.pdf

${ }^{3}$ https://files.eric.ed.gov/fulltext/ED436181.pdf
} 
System (Moodle). At the beginning of the activity the students must full fill an initial quiz about circuit theory. The game starts in a collaborative activity, the students can manipulate an AC panel experiment selecting resistor/capacitor values into a pre-defined circuit output, working with resistors in series and in parallel. The team that first finish correctly the puzzles win the game. The integration with the remote lab is implicit in the user interface, a game based layer was implemented inside the virtual world based on the remote experiment design. The controller occurs through an external hardware that sends data to the virtual objects inside the virtual world. The management of the data and communication is made through the SLOODE, a modified version of Moodle. Practical tests were made based on the user (students and educators) acceptance of the game. The validation showed positives responses from students acceptance of the collabora-tive aspect, as well as the interaction with the simulations and visualization of the circuit theory and operation. It was not specified in what context the game was applied or qualitative results.

Another integration technique is using augmented reality and virtual reality technologies. Hoffmann et al. (Hoffmann et al., 2016) designed a remote laboratory for engineering practices that can be manipulated by using virtual reality and gamepad controllers. The user is immersed in a virtual reality interface which allows the manipulation of the real robot arms. The user can control two cooperating six-axis robots to perform the tasks that they are ask for. The robots are controlled by two manual control panel and computers, that run the virtual reality simulation. The Nintendo Wii control is used to interact with the experiment. The validation of the game was made with engineering students of the RWTH Aachen University. Six questionnaires were applied during two practical tests: (1) theoretical, (2) pre-questionnaire of game experiences and spatial abilities, (3) first experiment, (4) questionnaire of the previous test, (5) second experiment, (6) questionnaire of the previous test. The tests include the evaluation of the correlation between the weekly gaming hours and the mechanism preferences of Wii control (direct or inverse kinematics). After the tests, it is possible to assume that the control mechanism is chosen depending on the task of the learning experience. The first and second experiments that the students performed were not described.

Other papers also described the application of questionnaires to evaluate the students experience using the integrated remote lab/game. The evaluations focused not only on the motivational and learning gains but also on entertainment and performance aspects of the game. Using learning management, Maja Atanasijević-Kunc et al. implemented a competition game in a remote laboratory device to teach multivariable control design (Atanasijevic-Kunc, Logar, Karba, Papic, \& Kos, 2011). Their work was based on the ECHO-system learning environment to the e-learning mana-gement, and on Matlab software to control design and simulation. The game is separated into three phases representing levels with a conceptual quiz, manipulation of a virtual laboratory simulation and remote experiment. In the first level, a questionnaire with three questions about multivariable systems is made available to the student. In the second level, the student must design a controller based on the rotation velocity and tension of an elastic band, and test the results using the simulation. Afterwards, the activity is reapplied using the remote experiment. The project occured during a three years at the Faculty of Electrical Engineering, at the University of Ljubljana, and in the final week of each semester a Likert questionnaire with 16 questions about technical efficiency and pedagogical aspects was applied. During these years the numbers of the students that used/do not used the e-learning and the percent of how many passed exams were accounted for. The results were satisfactory: all students that used the e-learning passed the exams, $50 \%$ of the students believed that the e-learning increased the freedom to organize the 
work and $42 \%$ that increased the studying efficacy.

In 2019, Tulha et al design and evaluated a digital game that provides real-time visualization and manipulation of the remote experiment "Conversion of Light Energy into Electrical Energy" (Tulha et al., 2019). The game is organized into six phases, each one about one concept of the photovoltaic effect, being: properties of light as electromagnetic radiation, electric energy with a circuit challenge, conductive materials concepts, and the relation between tension and angulation. During the last phase the student can manipulate the remote lab through the game interface. The game was applied Juan Orobio Goitia BHI School + Iurreta/Spain and was performed by 24 senior year students. After the use of the game the students full fill an inquiry based on MEEGA + (Model for the Evaluation of Educational Games). The question were organized based on the Likert model. Their implementation had positive outcomes, making possible to conclude that the students believes the game provides challenges, the contents helped them to become more confident about the subject and the game promotes cooperation.

Virtual instruments are also used in a game-like scenario such as LaboREM, a remote laboratory for electronics training (Luthon \& Larroque, 2015a). LaboREM enables to manipulate a robotic arm for placement of components in a gamified platform enabling collaborative work and learning itinerary adapted for training in electronics. The integration is made through a virtual manager that stores the data of the experiment, and schedules the queue of connected clients. This management enables the user to switch to other activities while is waiting, and to initialize the system. The proposed scenario follows various stages of lessons: including quizzes, remote labwork and a comparison with a simulator. Each lesson has a difficulty level. During the practical activities, a circuit must be build and tested at the simulator and the remote experiment with a limited time and trials. The activity can be done collaboratively, through chats and forum. The student can accumulate points and the best scores are published at the hall of fame with a Top 10. The evaluation was conducted during four years, each one with a class of science degree in an industrial engineering course. Two anonymous questionnaires were applied during each year, with 70 Likert questions about usability, student motivation and satisfaction. The result shows that $75 \%$ approves the platform as an effective educational strategy.

Zualkernan described the implementation of remote labs and game-based learning based on problem posing and problem-solving pedagogical methodology et al. (Zualkernan, Al Husaini, Loughlin, Mohebzada, \& El Gaml, 2012; Zualkernan et al., 2013). The collaborative experiment consists of two identical tanks of water, controlled through a digital interface. The player must try to keep his/her tank stable into a predefined setpoint, while attacks oscillating the opponent tank. The login to the game is made on Facebook, connected to the game as a socket client. The user can join or create his/her own room of the game. To validate the game, a case study was conducted with 12 chemistry students. The control group did not play the game, while the gaming group was divided into two teams. A quiz about the proportional integral control was applied before and after the activity. After the activity, the students also filled a Likert questionnaire about the aspects of the game were evaluated through were applied. The results indicated that 10 students felt immersive and motivated by the game, 11 believed the game improved the knowledge, and 10 would recommend the game. However, after playing the game once, the student performance in conceptual tests was not directly influenced. 


\subsection{Systematic Mapping Outcomes}

This subsection aims to group the papers surveyed and perform a brief analysis of the trends found. Data extraction of the mapping review yields 324 papers for the primary survey and 20 after the keywording phase (Table 3). Although most of the papers were found in Science Direct in the primary survey, all the accepted papers (10) were found in Scopus. Most papers surveyed in the mapped review were also found in the systematic review. Thus, we described the main characteristics, defined by the authors, related to the group in which the article is classified.

Table 3: Number of papers found during the mapping review..
\begin{tabular}{ccc} 
Data Base & Primary Survey & Keywording \\
\hline SciELO & - & - \\
Engineering Village & 15 & 2 \\
IEEE & 9 & 4 \\
Learn Tech Lib & 50 & - \\
Proquest & 76 & - \\
Science Direct & 95 & - \\
Scopus & 53 & 10 \\
Web of Science & 27 & 4 \\
\hline Total & 325 papers & 20 papers
\end{tabular}

Based on the research type facet, the keywording yield 4 groups. We classify the papers according to their research aims. The Theoretical Research group comprises all the conceptual works that describe theories or reviews. The Proposal Research group comprises all the studies that have already a development plan without implementation. The Prototype group are the papers that have a first implementation without evaluation data. Finally, the Validation Research group contains the papers that show some implementation and evaluation data, including usability tests or application in a classroom.

Three works surveyed were classified as Theoretical Research (Table 4). The theme of the papers can be summarized as reviews about the challenges and methodologies of the integration process. While Arango et al. (Arango, Aziz, Esche, \& Chassapis, 2008) describe the classification of games and the state of art of educational and training implementations, Orwin et al. (Orwin, Kist, Maxwell, \& Maiti, 2016) focus on the state of methodologies and theories of gamification elements into remote labs to provide foundations to the RALfie (Remote Access Laboratories for Fun, Innovation, and Education) project. Dziabenko et al. (Dziabenko \& García-Zubia, 2011) reviewed of technical concepts about the development of an educational game and the integration process with remote labs. The paper includes the description of necessary characteristics to integrate them efficiently.

Table 4: Theoretical Research.

\begin{tabular}{cccc} 
Year & Main Contribution & Reference & Source \\
\hline 2008 & $\begin{array}{c}\text { Review of education application of digital games, including } \\
\text { the integration with remote labs }\end{array}$ & (Arango et al., 2008) & {$[\mathrm{B}]$} \\
\hline 2011 & $\begin{array}{c}\text { Review of principles and theories to guide during the } \\
\text { integration of remotes labs into games }\end{array}$ & (Dziabenko \& García-Zubia, 2011) & [C] \\
\hline 2016 & $\begin{array}{c}\text { Review of theoretical educational foundations, gamification } \\
\text { design, in the context of RALfie project }\end{array}$ & (Orwin et al., 2016) & [D] \\
\hline
\end{tabular}

[A] Engineering Village [B] IEEE [C]Scopus [D] Web of Science 
Five proposal works were surveyed, listed in Table 5, of which three approaches the conception of architectures to structure the integration of the remote lab and the games. The proposals include design collaborative environments and an attractive interface. Cano et al. (Cano et al., 2016) propose a game-piece-based distributed architecture for remote laboratories. The laboratory space will support cybersecurity training based on instructional and motivational concepts. Kist et al. (Kist et al., 2016) propose a peer-to-peer approach based on gamification and quest-based learning. The proposed activities enable the user to build his/her remote lab with Matlab software support. Gil et al. (Rodriguez-Gil et al., 2016) proposes a generic architecture that can support the existing online laboratories paradigms and increase with serious-gaming elements. Arango et al. (Arango, Chang, Esche, \& Chassapis, 2007) and Aziz et al. (Aziz, Chang, Arango, Esche, \& Chassapis, 2007) are complementary research that discuss, respectively, the game design/pedagogical theories and existent methods to transfer information between the remote lab and the game.

Table 5: Proposal Research.

\begin{tabular}{cccc} 
Year & Proposal & Reference & Source \\
\hline 2007 & Data transfer data methods between the game and the remote lab & (Aziz et al., 2007) & {$[\mathrm{A}]$} \\
\hline 2007 & Pedagogical script for the use of remote lab at a \\
mechanical engineering course & (Arango et al., 2007) & \\
\hline 2016 & Architecture for the game as lab resources and the use of a remote lab in class & $($ Cano et al., 2016) & {$[\mathrm{C}]$} \\
\hline 2016 & Dissertation theme approaching an architecture to & (Rodriguez-Gil et al., 2016) & {$[\mathrm{C}]$} \\
\hline 2016 & Collaborative organization and architecture of RALfie project & (Kist et al., 2016) & {$[\mathrm{C}]$} \\
\hline
\end{tabular}

[A] Engineering Village [B] IEEE [C]Scopus [D] Web of Science

Two of the researches classified as Prototype propose solutions for the support of programming classes, including logic, algorithm and writing and debugging programs (Table 6). Guenaga et al. (Guenaga et al., 2014) and Itarrute et al. (Iturrate et al., 2013) described the incremental of the game with an augmented gamified world interface and the Google Blockly graphical progra-mming language, respectively. Tumkor et al. (Tumkor et al., 2012) described a multiplayer game laboratory environment that combines a remote lab with the virtual lab, enabling the share of variations.

Table 6: Prototype.

\begin{tabular}{|c|c|c|c|c|c|c|}
\hline Year & $\begin{array}{c}\text { Educational } \\
\text { Context }\end{array}$ & Didactic Focus & $\begin{array}{c}\text { Remote } \\
\text { Experiment }\end{array}$ & Enhancement & Reference & Source \\
\hline 2013 & $\begin{array}{c}\text { Multidisciplinary } \\
\text { school }\end{array}$ & $\begin{array}{l}\text { Basic programming } \\
\text { Algorithm } \\
\text { Logic principles }\end{array}$ & Robot & Google Blockly & (Iturrate et al., 2013) & {$[\mathrm{C}]$} \\
\hline 2013 & $\begin{array}{c}\text { Engineering } \\
\text { University }\end{array}$ & Basic fluid mechanisms & Flow rig experiment & - & (Tumkor et al., 2012) & {$[\mathrm{C}]$} \\
\hline 2014 & $\begin{array}{l}\text { Engineering } \\
\text { University }\end{array}$ & $\begin{array}{c}\text { Programming } \\
\text { logic and debugging }\end{array}$ & Robot & Augmented reality & (Guenaga et al., 2014) & {$[\mathrm{C}]$} \\
\hline
\end{tabular}

[A] Engineering Village [B] IEEE [C]Scopus [D] Web of Science

In the Validation Research group, two institutions were highlighted during the survey (Table 7). Luthon et al. (Luthon \& Larroque, 2015a), (Luthon, Petre, Steriu, \& Besleaga, 2009), (Luthon \& Larroque, 2015b), from the University of Pau, described in three papers researches made during 2009 to 2015 using LaboREM (Remote Laboratory) platform. LaboREM is a robot arm developed for training in electronics, including signal, circuits and system testing. The platform was 
tested in different scenarios during the years. Throughout the years, questionnaires were applied to verify the impact on student motivation, the experience during the activity and the platform usability. Mostly of the works describes the use of the Likert model as an evaluation methodology. Zualkernan et al. (Zualkernan et al., 2012), (Zualkernan et al., 2013), from the American University of Sharjah, described a collaborative methodology using problem posing for game-based learning in remote labs for proportional integral (PI) concepts. Twenty-two students were chosen randomly during the validation process, and a pre-quiz on PI controller was applied. After the use of the technology, the students fill out a survey about the student motivation and about the experience of playing the game. Maja Atanasijević-Kunc et al.(Atanasijevic-Kunc et al., 2011) focus on technical efficiency and the learning experience of competition game about multivariable control. Andrés-Gutiérrez et al. (Andrés-Gutiérrez, González, \& Gómez, 2010) made practical tests to analyze the performance of a solid motion game. The evaluation occurs through 16 questions based on Likert model. The enhancement of the integration process using other technological objects, like virtual reality or gamepad controller, is also a trend. Hoffmann et al. (Hoffmann et al., 2016), for example, focused on the evaluation of the use of a gamepad controller and the mechanisms preference of the user during the manipulation of a robot arm in a virtual gamified reality. Their work implemented two different experiences using kinematics into groups, giving to the participants questionnaires before and after the experiment. The conclusion was that the technical mechanism depends on the practical activity. Tulha et al. focus on the students perception of usability, learning and experience after used the game. The students were requested to the fill out a inquire based on MEEGA+ (Model for the Evaluation of Educational Games) organized based on the Likert model.

Table 7: Validation Research .

\begin{tabular}{|c|c|c|c|c|c|c|}
\hline Year & Educational Context & Didactic Focus & Enhancement & Evaluation & Reference & Source \\
\hline 2009 & $\begin{array}{l}\text { Technological } \\
\text { University }\end{array}$ & $\begin{array}{c}\text { Signal } \\
\text { Circuits } \\
\text { Systems testing }\end{array}$ & - & $\begin{array}{l}\text { Student Motivation } \\
\text { Usability Satisfaction }\end{array}$ & (Luthon et al., 2009) & [D] \\
\hline 2010 & $\begin{array}{l}\text { Engineering } \\
\text { University }\end{array}$ & Solid motion & Gamepad control & Practical test & (Andrés-Gutiérrez et al., 2010) & [D] \\
\hline 2011 & $\begin{array}{l}\text { Engineering } \\
\text { University }\end{array}$ & $\begin{array}{c}\text { Multivariable } \\
\text { Systems }\end{array}$ & Matlab & Practical test & (Atanasijevic-Kunc et al., 2011) & {$[\mathrm{C}]$} \\
\hline 2012 & $\begin{array}{l}\text { Chemical } \\
\text { University }\end{array}$ & $\begin{array}{l}\text { Proportional } \\
\text { integral }\end{array}$ & - & User experience & (Zualkernan et al., 2012) & {$[\mathrm{C}]$} \\
\hline 2013 & $\begin{array}{l}\text { Chemical } \\
\text { University }\end{array}$ & $\begin{array}{l}\text { Proportional } \\
\text { integral }\end{array}$ & - & $\begin{array}{l}\text { Student Motivation } \\
\text { Experience }\end{array}$ & (Zualkernan et al., 2013) & {$[\mathrm{B}]$} \\
\hline 2015 & $\begin{array}{l}\text { Engineering } \\
\text { University }\end{array}$ & Robot control & $\begin{array}{c}\text { Virtual Reality } \\
\text { Gamepad control }\end{array}$ & $\begin{array}{l}\text { Mechanisms } \\
\text { preference }\end{array}$ & (Hoffmann et al., 2016) & {$[\mathrm{C}]$} \\
\hline 2015 & $\begin{array}{l}\text { Technological } \\
\text { University }\end{array}$ & Basic electronic & - & Student Motivation & (Luthon \& Larroque, 2015b) & [D] \\
\hline 2015 & $\begin{array}{l}\text { Technological } \\
\text { University }\end{array}$ & Circuits & - & $\begin{array}{l}\text { Student Motivation } \\
\text { Platform Usability }\end{array}$ & (Luthon \& Larroque, 2015a) & {$[\mathrm{A}]$} \\
\hline 2019 & High School & $\begin{array}{l}\text { Photovoltaic } \\
\text { Effect }\end{array}$ & - & User Experience & (Tulha et al., 2019) & {$[\mathrm{B}]$} \\
\hline
\end{tabular}

[A] Engineering Village [B] IEEE [C]Scopus [D] Web of Science

The last phase of the systematic mapping review include the creation of a plot based on the papers found. Associating groups trend researches topics with the contributions facet we produced the mapping plot (Fig. 2). To reach our goal, we used a bubble plot based on the frequency of publications. The horizontal axes represent the research categories, respectively, (i) Theoretical, (ii) Proposal, (iii) Prototype, and (iv) Validation, previously described. The vertical axes repre- 
sent the contributions facet. We organize the contributions facet in 3 categories: (i) Integration process, including innovative architecture propose, (ii) Didactic, description of didactic activities, (iii) Design, description of interface design, including enhancements as virtual reality (listed in Fig. 2 respectively from the base to the top). The bubbles organization were based on the focus of papers surveyed, for example, if the research is theoretical and presents a review of integration guidelines is classify as integration.

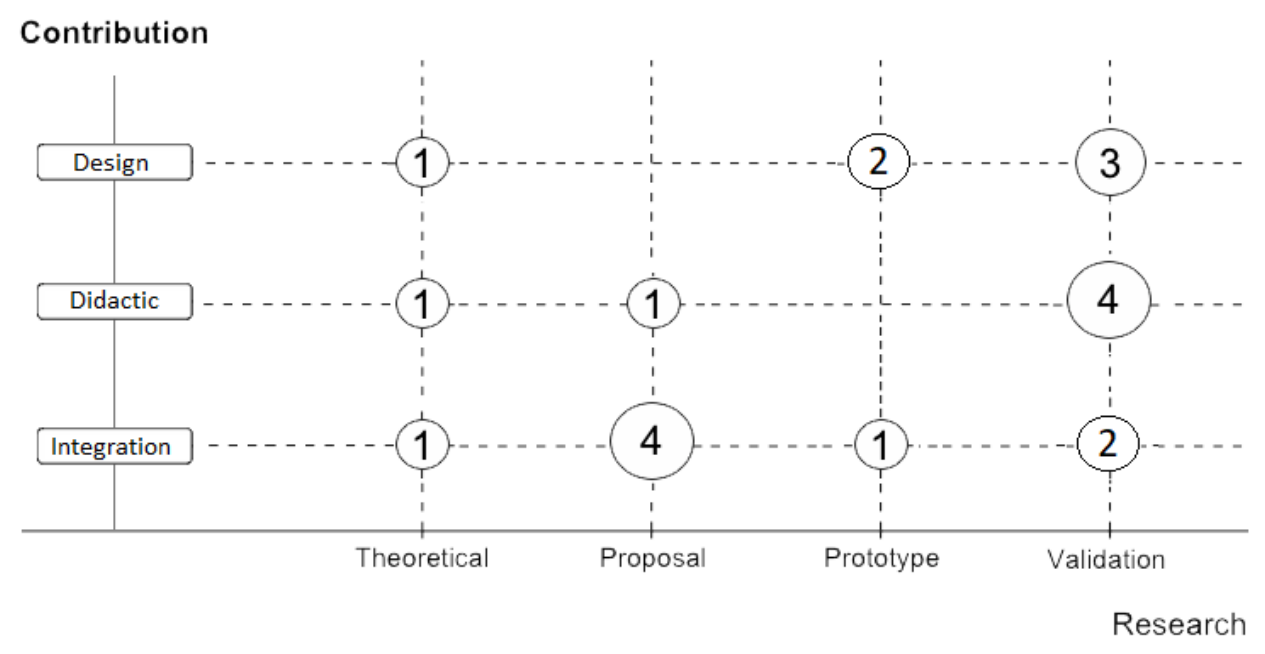

Figure 2: Categorical bubble plot for the systematic mapping. The horizontal axes represent the research categories proposed by our survey and the vertical axes the contributions facet, based on the description focus of the paper survey. .

Analyzing the bubble plot (Fig.2) is possible to regard that the Validation Research group is the large one, with 9 surveyed papers, however the sum of works on theoretical concepts, initial propositions or prototypes is still large than the works on validated results. The Theoretical group is formed with one literature review about each subject. The Proposal group has three researches describing new architectures to structure the integration process, one pedagogical script proposing activities and one dissertation theme. The Prototype group has one research describing simple implementation, and two describing design enhancements with others technologies. The Validation researches focus on student motivation, pedagogical impact was classify as didactic contribution, the usability evaluation as design contribution, and practical tests as integration contribution.

\section{Final Considerations}

The systematic review, as a summarizing process, makes possible deep verification and critical evaluation of different works in the literature. Our study aimed to find studies on the integration of remote laboratories and digital games, using a specific game based learning term. In contrast, the research tendency of the educational area was made clear with the mapping review.

During the research, we propose to answer questions to a better comprehension the integration of remote laboratories and digital games, including protocols, methodologies, and real cases of the use of remote labs and digital games in class. 
After the survey papers analysis, we conclude that although remote laboratories and digital games are separately consolidated tools, the integration of these tools is still its earlier phase. We found that it is possible to effectively integrate these objects and works describing implementation and data evaluation. However, the sum of papers on theoretical concepts, initial propositions or prototypes exceeds the number of validated works. Although six papers quantitatively describe the implementation and use of remote labs integrated into games in classes, only the game Circuit Warz was found available online.

Our systematic and mapping reviews showed no standard but different methods for integrating remote laboratories and digital games, probably because of the large diversity of digital games. The use of game elements design to manipulate the remote experiment is a trend of integration methods. Furthermore the use of "game based lab design" or "remote laboratory game" terms to refer to educational games based on remote laboratory architectures is common. Also, the most common integration methods found were the enhancement of remote laboratories and remote control by virtual or augmented reality. Whereas the former allows creating competition challenges, pointing out to the correct manipulations or gaming the interface, the latter allows manipulating the remote experiment by, for example, joysticks or gamepad support.

To evaluate the use of remote lab merged into games, $87.5 \%$ of works in the Validation Research group uses a Likert scale, which allow the students measure of their level of agreement with affirmations was a trend. The evaluation of experience after the use of the technologies shows positive results of enjoyed and motivational learning.

Although no limitation was applied to the publication year, $58 \%$ of the survey papers are dated before 2013. This rise some questions about why the research in this subject has decreased since them.

It is also noted that most of the papers were found in conference proceedings which suggests that the researches are not complete with technology assessments. This makes clear that integration of remote labs and digital games is still in the beginning.

\section{Acknowledgment}

The authors wish to express their gratitude to the following Brazilian research aid foundations: São Paulo Research Foundation (FAPESP - Process 2017/13805-8) and Higher Education Improvement Coordination (CAPES).

\section{References}

Andrés-Gutiérrez, J. J., González, M., \& Gómez, D. Z. (2010). MotionLab. In Education Engineering (EDUCON), 2010 IEEE (p. 1499-1506). IEEE. doi: 10.1109/EDUCON.2010.5492351 [GS Search]

Arango, F., Aziz, E.-S., Esche, S. K., \& Chassapis, C. (2008). A review of applications of computer games in education and training. In Frontiers in education conference, 2008. fie 2008. 38th annual, ieee (p. T4A-1-T4A-6). IEEE. doi: 10.1109/FIE.2008.4720514 [GS 


\section{Search]}

Arango, F., Chang, C., Esche, S. K., \& Chassapis, C. (2007). A scenario for collaborative learning in virtual engineering laboratories. In Frontiers in education conference-global engineering: Knowledge without borders, opportunities without passports, 2007. fie'07. 37th annual (p. F3G-7-F3G-12). IEEE. doi: 10.1109/FIE.2007.4417818 [GS Search]

Atanasijevic-Kunc, M., Logar, V., Karba, R., Papic, M., \& Kos, A. (2011). Remote multivariable control design using a competition game. IEEE Transactions on Education, 54(01), 97-103. doi: 10.1109/TE.2010.2046489 [GS Search]

Aziz, E.-S., Chang, C., Arango, F., Esche, S. K., \& Chassapis, C. (2007). Linking computer game engines with remote experiments. In Asme 2007 international mechanical engineering congress and exposition (p. 413-420). American Society of Mechanical Engineers. doi: 10.1115/IMECE2007-41969 [GS Search]

Bailey, J., Budgen, D., Turner, M., Kitchenham, B., Brereton, P., \& Linkman, S. (2007). Evidence relating to object-oriented software design: A survey. In First International Symposium on Empirical Software Engineering and Measurement, 2007. ESEM (p. 482-484). IEEE. doi: 10.1109/ESEM.2007.58 [GS Search]

Callaghan, M. J., McCusker, K., Losada, J. L., Harkin, J., \& Wilson, S. (2013). Using game-based learning in virtual worlds to teach electronic and electrical engineering. IEEE Transactions on Industrial Informatics, 9(1), p. 575-584. doi: 10.1109/TII.2012.2221133 [GS Search]

Cano, J., Hernández, R., Ros, S., \& Tobarra, L. (2016). A distributed laboratory architecture for game based learning in cybersecurity and critical infrastructures. In Remote engineering and virtual instrumentation (rev), 2016 13th international conference on (p. 183-185). IEEE. doi: 10.1109/REV.2016.7444461 [GS Search]

Casini, M., Prattichizzo, D., \& Vicino, A. (2003). E-learning by remote laboratories: A new tool for control education. IFAC Proceedings Volumes, 36(10), p. 73-78. doi: 10.1016/S14746670(17)33657-1 [GS Search]

Dziabenko, O., \& García-Zubia, J. (2011). Remote experiments and online games: How to merge them? Global Engineering Education Conference (EDUCON), 2011 IEEE, p. 1102-1107. doi: 10.1109/EDUCON.2011.5773285 [GS Search]

Fabbri, S., Silva, C., Hernandes, E., Octaviano, F., Di Thommazo, A., \& Belgamo, A. (2016). Improvements in the start tool to better support the systematic review process. In Proceedings of the 20th international conference on evaluation and assessment in software engineering (p. 1-5). ACM. doi: 10.1145/2915970.2916013 [GS Search]

Guenaga, M., Menchaca, I., de Guinea, A. O., Dziabenko, O., García-Zubía, J., \& Salazar, M. (2014). Serious games, remote laboratories and augmented reality to develop and assess programming skills. In Frontiers in gaming simulation (p. 29-36). Springer. doi: 10.1007/9783-319-04954-0_4 [GS Search]

Hoffmann, M., Plumanns, L., Lenz, L., Schuster, K., Meisen, T., \& Jeschke, S. (2016). Enhancing the learning success of engineering students by virtual experiments. In Automation, communication and cybernetics in science and engineering 2015/2016 (p. 267-279). Springer. doi: 10.1007/978-3-319-46916-4_26 [GS Search]

Iturrate, I., Martín, G., García-Zubia, J., Angulo, I., Dziabenko, O., Orduña, P., ... Fidalgo, A. (2013). A mobile robot platform for open learning based on serious games and remote laboratories. In Engineering education (cispee), 2013 1st international conference of the portuguese society for (p. 1-7). IEEE. doi: 10.1109/CISPEE.2013.6701970 [GS Search] 
Kist, A. A., Maiti, A., Maxwell, A. D., Orwin, L., Albion, P., \& Ting, W. (2016). The game and activity environment of ralfie: Remote access laboratories for fun, innovation and education. In Remote engineering and virtual instrumentation (rev), 2016 13th international conference on (p. 324-325). IEEE. doi: 10.1109/REV.2016.7444492 [GS Search]

Kitchenham, B. (2004). Procedures for performing systematic reviews. Keele, UK, Keele University, 33(2004), p. 1-26. [GS Search]

Luthon, F., \& Larroque, B. (2015a). Laborem: A remote laboratory for game-like training in electronics. IEEE Transactions on learning technologies, 8(3), p. 311-321. doi: 10.1109/TLT.2014.2386337 [GS Search]

Luthon, F., \& Larroque, B. (2015b). Remote laboratory for game-based distance learning in electronics. In 4th international conference on electronics, communications and networks (cecnet 2014). CECNet. doi: hal-01103183 [GS Search]

Luthon, F., Petre, A., Steriu, D., \& Besleaga, A. (2009). Laborem: open lab for remote work. In 2009 3rd international conference on signals, circuits and systems (scs) (p. 1-6). IEEE. doi: 10.1109/ICSCS.2009.5412343 [GS Search]

Müller, D., \& Erbe, H.-H. (2007). Collaborative remote laboratories in engineering education: Challenges and visions. Advances on remote laboratories and e-learning experiences, $\mathrm{p}$. 35-59. [GS Search]

Nedic, Z., Machotka, J., \& Nafalski, A. (2003). Remote laboratories versus virtual and real laboratories (Vol. 1) (No. 1). 33rd Annual Frontiers in Education, 2003. FIE 2003. doi: 10.1109/FIE.2003.1263343 [GS Search]

Oblinger, D. (2004). The next generation of educational engagement. Journal of interactive media in education, 2004(1), p. Art. 10. doi: 10.5334/2004-8-oblinger [GS Search]

Orwin, L., Kist, A. A., Maxwell, A. D., \& Maiti, A. (2016). Using gamification to create opportunities for engagement, collaboration and communication in a peer-to-peer environment for making and using remote access labs. In Experiment@ international conference (ex at'15), 2015 3rd (p. 230-236). IEEE. doi: 10.1109/EXPAT.2015.7463271 [GS Search]

Papastergiou, M. (2009). Digital game-based learning in high school computer science education: Impact on educational effectiveness and student motivation. Computers \& education, 52(1), p. 1-12. doi: 10.1016/j.compedu.2008.06.004 [GS Search]

Petersen, K., Feldt, R., Mujtaba, S., \& Mattsson, M. (2008). Systematic mapping studies in software engineering. In 12th International Conference on Evaluation and Assessment in Software Engineering, EASE (Vol. 8, p. 68-77). Science Open. doi: 10.14236/ewic/EASE2008.8 [GS Search]

Pivec, M., \& Kearney, P. (2007). Games for learning and learning from games. Organizacija, Journal of Management, Information and Human Resources, 40(6), p. 267-272. [GS Search]

Prensky, M. (2003, October). Digital game-based learning. Computers in Entertainment, 1(1), p. 21. doi: 10.1145/950566.950596 [GS Search]

Rodriguez-Gil, L., García-Zubia, J., \& Orduña, P. (2016). An architecture for new models of online laboratories: Educative multi-user gamified hybrid laboratories based on virtual environments. In 2016 13th international conference on remote engineering and virtual instrumentation (rev) (p. 202-203). IEEE. doi: 10.1109/REV.2016.7444465 [GS Search]

Sampaio, R. F., \& Marcini, M. C. (2007). Estudos de revisão sistemática: um guia para síntese criteriosa da evidência científica. Revista Brasileira de Fisioterapia, 11(1), p. 83-89. doi: 10.1590/S1413-35552007000100013 [GS Search] 
Tulha, C. N., Carvalho, M. A. G., \& Coluci, V. R. (2019). Educational digital game integrated into a remote laboratory for learning physic concepts. In 2019 IEEE 19th International Conference on Advanced Learning Technologies (ICALT) (Vol. 2161, p. 234-235). IEEE. doi: 10.1109/ICALT.2019.00079 [GS Search]

Tumkor, S., Zhang, M., Zhang, Z., Chang, Y., Esche, S. K., \& Chassapis, C. (2012). Integration of a real-time remote experiment into a multi-player game laboratory environment. In ASME 2012 International Mechanical Engineering Congress and Exposition (p. 181-190). American Society of Mechanical Engineers. doi: 10.1115/IMECE2012-86944 [GS Search]

Zualkernan, I. A., Al Husaini, G. G., Loughlin, K. F., Mohebzada, J. G., \& El Gaml, M. (2012). Using problem posing, problem solving for game-based learning in remote labs. In 2012 IEEE 12th International Conference on Advanced Learning Technologies (ICALT) (Vol. 1, p. 716-717). IEEE. doi: 10.1109/ICALT.2012.179 [GS Search]

Zualkernan, I. A., Husseini, G. A., Loughlin, K. F., Mohebzada, J. G., \& El Gaml, M. (2013). Remote labs and game-based learning for process control. Chemical Engineering Education, 47(3), p. 179-188. [GS Search] 